NASA Technical Memorandum 105757

\title{
IN-64
}

NASA Technical Memorandum 105757

$$
\begin{array}{r}
160258 \\
P .17
\end{array}
$$

\section{A Brief Description of a New Numerical Framework for Solving Conservation Laws-The Method of Space-Time Conservation Element and Solution Element}

Sin-Chung Chang

National Aeronautics and Space Administration

Lewis Research Center

Cleveland, Ohio

and

Wai-Ming To

Sverdrup Technology, Inc.

Lewis Research Center Group

Brook Park, Ohio

Prepared for the

13th International Conference on Numerical Methods

in Fluid Dynamics

Rome, Italy, July 6-10, 1992
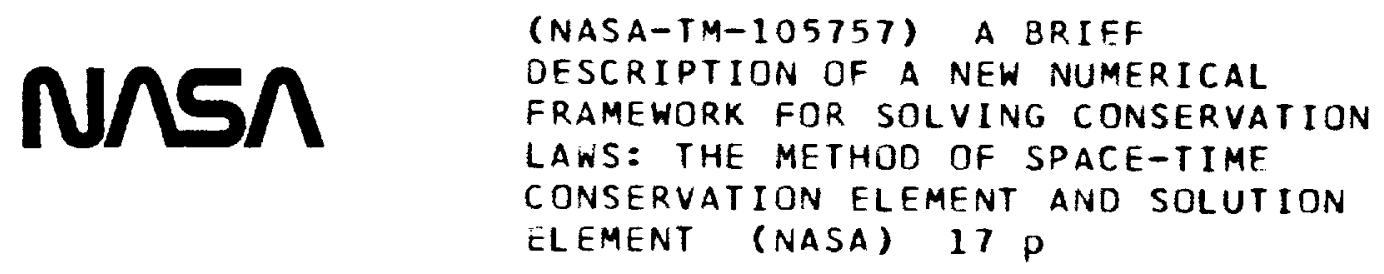


\title{
A BRIEF DESCRIPTION OF A NEW NUMERICAL FRAMEWORK FOR SOLVING CONSERVATION LAWS - THE METHOD OF SPACE-TIME CONSERVATION ELEMENT AND SOLUTION ELEMENT §
}

\author{
S.C. Chang $\dagger$ and W.M. To $\ddagger$ \\ $\dagger$ NASA Lewis Research Center, Cleveland, Ohio 44135, U.S.A. \\ $\ddagger$ Sverdrup Technology, Inc., Cleveland, Ohio 44142, U.S.A.
}

\section{INTRODUCTION}

In this paper we shall describe a new numerical method for solving conservation laws. It is much simpler than a typical high resolution method [1]. No flux limiter or any characteristicsbased technique is involved. No artificial viscosity or smoothing is introduced, and no moving mesh is used. Yet this method is capable of generating highly accurate shock tube solutions. The slight numerical overshoot and/or oscillations generated can be removed if a simple averaging formula initially used is replaced by a weighted averaging formula. This modification has no discernable effect on other parts of the solution. Because of its simplicity, multi-dimension generalization is straightforward and it allows for the simultaneous treatment of variables in different spatial directions.

\section{CONSERVATION LAWS}

We consider a dimensionless form of the 1-D unsteady Euler equations for an ideal gas. Let $\rho, u, p$, and $\gamma$, respectively, be the mass density, velocity, static pressure, and constant specific heat ratio. Let

$$
\left.\begin{array}{c}
q_{1}=\rho, \quad q_{2}=\rho u, \quad q_{3}=p /(\gamma-1)+(1 / 2) \rho u^{2} \\
f_{1}=q_{2} \\
f_{2}=(\gamma-1) q_{3}+(1 / 2)(3-\gamma)\left(q_{2}\right)^{2} / q_{1} \\
f_{3}=\gamma q_{2} q_{3} / q_{1}-(1 / 2)(\gamma-1)\left(q_{2}\right)^{3} /\left(q_{1}\right)^{2}
\end{array}\right\}
$$

Then the Euler equations can be expressed as

$$
\partial q_{m} / \partial t+\partial f_{m} / \partial x=0 \quad, \quad m=1,2,3
$$

$\S$ This work is dedicated to the memory of a teacher, Mr. Nylon Cheng 
Let $x_{1}=x$ and $x_{2}=t$ be considered as the coordinates of a two-dimensional Euclidean space $E_{2}$. The integral form of Eq. (2.3) in the space-time $E_{2}$ can be expressed as (see Fig. 1)

$$
\oint_{S(V)} \vec{h}_{m} \cdot \overrightarrow{d s}=0 \quad, \quad m=1,2,3
$$

where (i) $S(V)$ is the boundary of an arbitrary space-time volume $V$ in $E_{2},(i i) \vec{h}_{m}=\left(f_{m}, q_{m}\right)$ are space-time current density vectors in $E_{2}$, and (iii) $\overrightarrow{d s}=d \sigma \vec{n}$ with $d \sigma$ and $\vec{n}$, respectively, being the area and the outward unit normal of a surface element on $S(V)$. Note that $(i) \vec{h}_{m} \cdot \overrightarrow{d s}_{s}$ is the space-time flux of $\vec{h}_{m}$ leaving the volume $V$ through the surface element $\overrightarrow{d s}$, and (ii) all mathematical operations can be carried out as though $E_{2}$ is an ordinary two-dimensional Euclidean space.

\section{NUMERICAL METHOD}

Let $E_{2}$ be divided into nonoverlapping thombic regions (see Fig. 2) referred to as solution elements (SEs). Each SE is centered at a mesh point $(j, n)$ where $n=0,1 / 2,1,3 / 2, \cdots$, and $j=$ $(n \pm 1 / 2),(n \pm 3 / 2), \cdots$, i.e., $j$ is a half-integer (whole integer) if $n$ is a whole integer (half-integer). In other words, $j$ and $n$ are both whole integers or both half-integers if, as occurring in Fig. 2, a SE is centered at the mesh point $(j, n+1 / 2)$. Thus, the locations of SEs and their centers are staggered over every half time-step. A SE centered at $(j, n)$, and its interior are denoted by $\operatorname{SE}(j, n)$ and $\operatorname{SE}^{\prime}(j, n)$, respectively.

For any $(x, t) \in \operatorname{SE}^{\prime}(j, n), q_{m}(x, t), f_{m}(x, t)$, and $\vec{h}_{m}(x, t)$, respectively, are approximated by $\underline{q}_{m}(x, t ; j, n), \underline{f}_{m}(x, t ; j, n)$, and $\vec{h}_{m}(x, t ; j, n)$ which we shall define immediately. Let

$$
q_{m}(x, t ; j, n)=\left(\sigma_{m}\right)_{j}^{n}+\left(\alpha_{m}\right)_{j}^{n}\left(x-x_{j}\right)+\left(\beta_{m}\right)_{j}^{n}\left(t-t^{n}\right) \quad, \quad m=1,2,3
$$

where $\left(\sigma_{m}\right)_{j}^{n},\left(\alpha_{m}\right)_{j}^{n}$, and $\left(\beta_{m}\right)_{j}^{n}$ are constants in $\operatorname{SE}^{\prime}(j, n)$, and $\left(x_{j}, t^{n}\right)$ are the coordinates of the mesh point $(j, n)$. Note that

$$
\underline{q}_{m}\left(x_{j}, t^{n} ; j, n\right)=\left(\sigma_{m}\right)_{j}^{n}, \quad \partial \underline{q}_{m}(x, t ; j, n) / \partial x=\left(\alpha_{m}\right)_{j}^{n}, \quad \partial \underline{q}_{m}(x, t ; j, n) / \partial t=\left(\beta_{m}\right)_{j}^{n}
$$

Moreover, if we identify $\left(\sigma_{m}\right)_{j}^{n},\left(\alpha_{m}\right)_{j}^{n}$, and $\left(\beta_{m}\right)_{j}^{n}$, respectively, with the values of $q_{m}, \partial q_{m} / \partial x$, and $\partial q_{m} / \partial t$ at $\left(x_{j}, t^{n}\right)$, the expression on the right side of Eq. (3.1) becomes the first-order Taylor's expansion of $q_{m}(x, t)$ at $\left(x_{j}, t^{n}\right)$. As a result of these considerations, $\left(\sigma_{m}\right)_{j}^{n},\left(\alpha_{m}\right)_{j}^{n}$, and $\left(\beta_{m}\right)_{j}^{n}$ will be considered as the numerical analogues of the values of $q_{m}, \partial q_{m} / \partial x$, and $\partial q_{m} / \partial t$ at $\left(x_{j}, t^{n}\right)$, respectively.

Let $f_{m}(x, t ; j, n), m=1,2,3$, be defined in terms of $q_{m}(x, t ; j, n), m=1,2,3$, according to Eq. (2.2) with the understanding that $f_{m}$ and $q_{m}$ in Eq. (2.2) be replaced by $f_{m}(x, t ; j, n)$ and $q_{m}(x, t ; j, n)$, respectively. Using Eq. (3.1), $f_{m}(x, t ; j, n)$ is expressed as a function of $\left(x-x_{j}\right)$ and $\left(t-t^{n}\right)$, and then expanded as a power series of them. The new method is simplified by truncating 
the power series after first-order terms. This is consistent with the first-order approximation given in Eq. (3.1). In the new method, only $f_{m}$ at $x=x_{j}$ are needed. Let $\sigma_{m}=\left(\sigma_{m}\right)_{j}^{n}$ and $\beta_{m}=$ $\left(\beta_{m}\right)_{j}^{n}$. Then explicitly, we have:

$$
\begin{gathered}
\underline{f}_{1}\left(x_{j}, t ; j, n\right)=\sigma_{2}+\beta_{2}\left(t-t^{n}\right) \\
\underline{f}_{2}\left(x_{j}, t ; j, n\right)=(\gamma-1) \sigma_{3}+(1 / 2)(3-\gamma)\left(\sigma_{2}\right)^{2} / \sigma_{1} \\
+\left[(\gamma-1) \beta_{3}+(3-\gamma)\left(\sigma_{2} \beta_{2} / \sigma_{1}\right)-(1 / 2)(3-\gamma)\left(\sigma_{2} / \sigma_{1}\right)^{2} \beta_{1}\right]\left(t-t^{n}\right) \\
\underline{f}_{3}\left(x_{j}, t ; j, n\right)=\gamma \sigma_{2} \sigma_{3} / \sigma_{1}-(1 / 2)(\gamma-1)\left(\sigma_{2}\right)^{3} /\left(\sigma_{1}\right)^{2}+\left\{\gamma \left[\left(\sigma_{2} \beta_{3}+\sigma_{3} \beta_{2}\right) / \sigma_{1}\right.\right. \\
\left.\left.-\sigma_{2} \sigma_{3} \beta_{1} /\left(\sigma_{1}\right)^{2}\right]+(1 / 2)(\gamma-1)\left[2\left(\sigma_{2} / \sigma_{1}\right)^{3} \beta_{1}-3\left(\sigma_{2} / \sigma_{1}\right)^{2} \beta_{2}\right]\right]\left(t-t^{n}\right)
\end{gathered}
$$

Since $\vec{h}_{m}=\left(f_{m}, q_{m}\right)$, we define $\vec{h}_{m}(x, t ; j, n)=\left(\underline{f}_{m}(x, t ; j, n), q_{m}(x, t ; j, n)\right)$.

Let $E_{2}$ be divided into nonoverlapping rectangular regions (see Fig. 2) referred to as conservation elements (CEs). They are also staggered over every half time-step. Let the CE with its upper edge centered at $(j, n)$ be denoted by $\operatorname{CE}(j, n)$. Then the current approximation of Eq. (2.4) is

$$
\oint_{S(\mathrm{CE}(j, n))} \overrightarrow{\underline{h}}_{m} \cdot \overrightarrow{d s}=0 \quad \text { (all possible } m \text { and }(j, n) \text { ) }
$$

Because the entire boundary (except for three isolated points) of a CE is located within the interiors of three neighboring SEs, $\vec{h}_{m}$ is continuous across any interface separating two neighboring CEs. Thus Eq. (3.6) will remain valid if $\operatorname{CE}(j, n)$ is replaced by the union of any combination of CEs.

Because each $S(\operatorname{CE}(j, n))$ is a simple closed curve in $E_{2}$ (see Fig. 1), the surface integration form Eq. (3.6) can be converted into a line integration form [2, p.14], i.e.,

$$
\oint_{S(C E(j, n))} \vec{g}_{m} \cdot \overrightarrow{d r}=0 \quad \text { ( all possible } m \text { and }(j, n) \text { ) }
$$

where $\overrightarrow{\underline{g}}_{m}=\left(-q_{m}, \underline{f}_{m}\right)$ and $\overrightarrow{d r}=(d x, d t)$.

For each $\operatorname{SE}(j, n)$, let

$$
\begin{gathered}
s_{1}(j, n)=(\Delta x / 8) \alpha_{1}+(1 / 2)(\Delta t / \Delta x)\left[\sigma_{2}+(\Delta t / 4) \beta_{2}\right] \\
s_{2}(j, n)=(\Delta x / 8) \alpha_{2}+(1 / 2)(\Delta t / \Delta x)\left[(\gamma-1) \sigma_{3}+(1 / 2)(3-\gamma)\left(\sigma_{2}\right)^{2} / \sigma_{1}\right] \\
+(1 / 8)\left[(\Delta t)^{2} / \Delta x\right]\left\{(\gamma-1) \beta_{3}+(3-\gamma)\left[\sigma_{2} \beta_{2} / \sigma_{1}-(1 / 2)\left(\sigma_{2} / \sigma_{1}\right)^{2} \beta_{1}\right]\right\} \\
s_{3}(j, n)=(\Delta x / 8) \alpha_{3}+(1 / 2)(\Delta t / \Delta x)\left[\gamma \sigma_{2} \sigma_{3} / \sigma_{1}-(1 / 2)(\gamma-1)\left(\sigma_{2}\right)^{3} /\left(\sigma_{1}\right)^{2}\right]+(1 / 8)\left[(\Delta t)^{2} / \Delta x\right] \\
\times\left\{\left(\gamma / \sigma_{1}\right)\left(\sigma_{2} \beta_{3}+\sigma_{3} \beta_{2}-\sigma_{2} \sigma_{3} \beta_{1} / \sigma_{1}\right)+(\gamma-1)\left[\left(\sigma_{2} / \sigma_{1}\right)^{3} \beta_{1}-(3 / 2)\left(\sigma_{2} / \sigma_{1}\right)^{2} \beta_{2}\right]\right\}
\end{gathered}
$$


where $\sigma_{m}=\left(\sigma_{m}\right)_{j}^{n}, \alpha_{m}=\left(\alpha_{m}\right)_{j}^{n}$, and $\beta_{m}=\left(\beta_{m}\right)_{j}^{n}$. Then Eq. (3.7) implies that, for each $\operatorname{SE}(j, n+1 / 2)$,

$\left(\sigma_{m}\right)_{j}^{n+1 / 2}=(1 / 2)\left[\left(\sigma_{m}\right)_{j-1 / 2}^{n}+\left(\sigma_{m}\right)_{j+1 / 2}^{n}\right]+s_{m}(j-1 / 2, n)-s_{m}(j+1 / 2, n), \quad m=1,2,3$

i.e., $\left(\sigma_{m}\right)_{j}^{n+1 / 2}$ is determined in terms of the numerical variables associated with $\operatorname{SE}(j-1 / 2, n)$ and $\operatorname{SE}(j+1 / 2, n)$. Similar formulae for $\left(\alpha_{m}\right)_{j}^{n+1 / 2}$ and $\left(\beta_{m}\right)_{j}^{n+1 / 2}$ will be given next.

Let $A_{+}, A$, and $A_{-}$(see Fig. 2) denote $\left(x_{j+1 / 2}, t^{n+1 / 2}\right),\left(x_{j}, t^{n+1 / 2}\right)$, and $\left(x_{j-1 / 2}, t^{n+1 / 2}\right)$, respectively. Let

$$
q_{m \pm}=q_{m}\left(x_{j \pm 1 / 2}, t^{n+1 / 2} ; j \pm 1 / 2, n\right)
$$

Because $A_{ \pm}$do not belong to $S^{\prime}(j \pm 1 / 2, n)$, the expression on the right side of Eq. (3.12) is to be evaluated at the two points immediately below them. A central-difference formula for evaluating $\left(\alpha_{m}\right)_{j}^{n+1 / 2}$, the numerical analogue of $\partial q_{m} / \partial x$ at point $A$, is

$$
\left(\alpha_{m}\right)_{j}^{n+1 / 2}=\left(q_{m+}-q_{m-}\right) / \Delta x
$$

This formula is valid as long as no discontinuity of $q_{m}$ (or its derivatives) occurs between $A_{-}$and $A_{+}$. In the following discussion, we develop an altemate which is valid even in the presence of discontinuity.

Let

$$
\left(\alpha_{m \pm}\right)_{j}^{n+1 / 2}= \pm\left[q_{m \pm}-\left(\sigma_{m}\right)_{j}^{n+1 / 2}\right] /(\Delta x / 2)
$$

where $\left(\sigma_{m}\right)_{j}^{n+1 / 2}$ has just been obtained using Eq. (3.11). Because $q_{m+},\left(\sigma_{m}\right)_{j}^{n+1 / 2}$, and $q_{m-}$ are the numerical analogues of $q_{m}$ at $A_{+}, A$, and $A_{-}$, respectively, $\left(\alpha_{m+}\right)_{j}^{n+1 / 2}$ and $\left(\alpha_{m-}\right)_{j}^{n-1 / 2}$ are two numerical analogues of $\partial q_{m}\left(x_{j}, l^{n+1 / 2}\right) / \partial x$ with one being evaluated from the right and another from the left. Note that $\left(\alpha_{m}\right)_{j}^{n+1 / 2}$ defined by Eq. (3.13) is equal to the average of $\left(\alpha_{m+}\right)_{j}^{n+1 / 2}$ and $\left(\alpha_{m-}\right)_{j}^{n+1 / 2}$.

In case that a discontinuity occurs between $A$ and $A_{+}$but not between $A$ and $A_{-}$, one would expect that $\left|\left(\alpha_{m+}\right)_{j}^{n+1 / 2}\right| \gg\left|\left(\alpha_{m-}\right)_{j}^{n+1 / 2}\right|$. Moreover, because $A$ and $A$ - are on the same side of the discontinuity while $A$ and $A_{+}$are on the opposite sides, $\left(\alpha_{m}\right)_{j}^{n+1 / 2}$ should be closer to $\left(\alpha_{m-}\right)_{j}^{n+1 / 2}$ than $\left(\alpha_{m+}\right)_{j}^{n+1 / 2}$. This observation suggests that $\left(\alpha_{m}\right)_{j}^{n+1 / 2}$ should be a weighted average of $\left(\alpha_{m+}\right)_{j}^{n+1 / 2}$ and $\left(\alpha_{m-}\right)_{j}^{n+1 / 2}$ biased toward the one with the smaller magnitude.

As a result of the above and other considerations [3], Eq. (3.13) will be generalized by

$$
\left(\alpha_{m}\right)_{j}^{n+1 / 2}=F\left(\left(\alpha_{m-}\right)_{j}^{n+1 / 2},\left(\alpha_{m+}\right)_{j}^{n+1 / 2} ; c\right)
$$

Here $c \geq 0$ is an adjustable constant and the function $F$ is defined by $(i) F(0,0 ; c)=0$ and (ii) 


$$
F\left(\alpha, \alpha_{+} ; c\right)=\left(\left|\alpha_{+}\right|^{c} \alpha+\mid \alpha^{c} \alpha_{+}\right) /\left(\left|\alpha_{+}\right|^{c}+\left|\alpha_{\mid}\right|^{c}\right) \quad, \quad\left(\left|\alpha_{+}\right|+\left|\alpha_{-}\right|>0\right)
$$

where $\alpha$ and $\alpha_{+}$are any two real variables. Note that $F\left(\alpha_{-}, \alpha_{+} ; c\right)=\left(\alpha_{+}+\alpha_{+}\right) / 2$ if $c=0$ or $|\alpha|$ $=\left|\alpha_{+}\right|$, i.e., Eq. (3.15) is reduced to Eq. (3.13) if $c=0$ or $|\alpha|=\left|\alpha_{+}\right|$. Also the expression on the right side of Eq. (3.16) represents a weighted average of $\alpha$ and $\alpha_{+}$with the weight factors $\left|\alpha_{+}\right|^{c} /\left(\left|\alpha_{+}\right|^{c}+\left|\alpha_{-}\right|^{c}\right)$ and $|\alpha|^{c} /\left(\left|\alpha_{+}\right|^{c}+\left|\alpha_{-}\right|^{c}\right)$. For $c>0$, this average is biased toward the one among $\alpha$ and $\alpha_{+}$with the smaller magnitude. For the same values of $\left|\alpha_{+}\right|$and $|\alpha|$, the bias increases as $c$ increases.

Substituting Eq. (2.2) into Eq. (2.3), one obtains three equations in which $\partial q_{m} / \partial t, m=1,2,3$, are expressed in terms of $q_{m}$ and $\partial q_{m} / \partial x, m=1,2,3$. Let $q_{m}$ and their derivatives be replaced by the corresponding numerical analogues at the mesh point $(j, n+1 / 2)$, one obtains that

$$
\begin{gathered}
\left(\beta_{1}\right)_{j}^{n+1 / 2}=-\alpha_{2} \\
\left(\beta_{2}\right)_{j}^{n+1 / 2}=(1 / 2)(3-\gamma)\left(\sigma_{2} / \sigma_{1}\right)^{2} \alpha_{1}-(3-\gamma)\left(\sigma_{2} / \sigma_{1}\right) \alpha_{2}-(\gamma-1) \alpha_{3} \\
\left(\beta_{3}\right)_{j}^{n+1 / 2}=\left[\gamma \sigma_{2} \sigma_{3} /\left(\sigma_{1}\right)^{2}-(\gamma-1)\left(\sigma_{2} / \sigma_{1}\right)^{3}\right] \alpha_{1} \\
+\left[(3 / 2)(\gamma-1)\left(\sigma_{2} / \sigma_{1}\right)^{2}-\gamma \sigma_{3} / \sigma_{1}\right] \alpha_{2}-\gamma\left(\sigma_{2} / \sigma_{1}\right) \alpha_{3}
\end{gathered}
$$

where $\sigma_{m}=\left(\sigma_{m}\right)_{j}^{n+1 / 2}$ and $\alpha_{m}=\left(\alpha_{m}\right)_{j}^{n+1 / 2}$.

With the aid of Eqs. (3.11), (3.15), and (3.17) - (3.19), $\left(\sigma_{m}\right)_{j}^{n},\left(\alpha_{m}\right)_{j}^{n}$, and $\left(\beta_{m}\right)_{j}^{n}$ can be determined in terms of the initial values $\left(\sigma_{m}\right)_{ \pm 1 / 2}^{0},\left(\sigma_{m}\right)_{ \pm 3 / 2}^{0}, \cdots$, and $\left(\alpha_{m}\right)_{ \pm 1 / 2}^{0},\left(\alpha_{m}\right)_{ \pm 3 / 2}^{0}, \cdots$.

\section{NUMERICAL RESULTS}

We consider a shock tube problem used by Sod [4]. Let $\gamma=1.4$. At $t=0$, let $(i)(\rho, u, p)=$ $(1,0,1)$, i.e., $\left(q_{1}, q_{2}, q_{3}\right)=(1,0,2.5)$, if $x<0$, and $(i i)(p, u, p)=(0.125,0,0.1)$, i.e., $\left(q_{1}, q_{2}, q_{3}\right)=$ $(0.125,0,0.25)$, if $x>0$. Thus

$$
\left(\left(\sigma_{1}\right)_{j}^{0},\left(\sigma_{2}\right)_{j}^{0},\left(\sigma_{3}\right)_{j}^{0}\right)= \begin{cases}(1,0,2.5) & \text { if } j=-1 / 2,-3 / 2, \cdots \\ (0.125,0,0.25) & \text { if } j=1 / 2,3 / 2, \cdots\end{cases}
$$

and $(i i)\left(\alpha_{m}\right)_{j}^{0}=0, j= \pm 1 / 2, \pm 3 / 2, \cdots$. Eqs. $(3.17)-(3.19)$ imply that $\left(\beta_{m}\right)_{j}^{0}=0, j= \pm 1 / 2, \pm 3 / 2$, $\cdots$.

The above initial conditions, and Eqs. (3.11), (3.15), and (3.17) - (3.19), imply that $\left(\sigma_{m}\right)_{j}^{n}$, $\left(\alpha_{m}\right)_{j}^{n}$, and $\left(\beta_{m}\right)_{j}^{n}$ are constant in two separate regions which, respectively, are defined by $j \leq$ $-(\mathrm{n}+1 / 2)$ and $j \geq(\mathrm{n}+1 / 2)$. Thus one needs to evaluate the above variables only if $(\mathrm{n}+1 / 2)>|j|$.

The current scheme is stable if $C F L=\max (|u|+|a|) \Delta t / \Delta x \leq 1$ [3]. Here $a=$ local sound speed. In the current computations, $\Delta x=0.01, \Delta t=0.004$, and $C F L \doteq 0.88$. Numerical results (dots) at $t=0.4$ are compared with the exact solutions (solid lines) in Fig. 3. Since each 
marching step advances the solution from $t$ to $t+\Delta t / 2$, these results are obtained after 200 steps. Note that (i) shock discontinuity is resolved almost within one mesh interval, and (ii) the slight numerical overshoot and oscillations generated when $c=0$ essentially disappear when $c=1$ is used.

\section{CONCLUSIONS AND DISCUSSIONS}

The current scheme has a stencil containing only two points. This minimization of stencil has the effect of reducing numerical diffusion [5]. It is achieved by including $\left(\alpha_{m}\right)_{j}^{n}$ and $\left(\beta_{m}\right)_{j}^{n}$ as numerical variables. The fluxes at an interface separating two CEs are evaluated with no interpolation or extrapolation. Accuracy of flux evaluation is enhanced by requiring that the solution given in Eq. (3.1) satisfies the Euler equations at the center of every SE. This makes the use of characteristics-based techniques less necessary. The above key features all contribute to the simplicity, generality, and accuracy of the current scheme. They all owe their existence to the use of staggered SEs and CEs.

In the current method, flux evaluation within each $\operatorname{SE}(j, n)$ is required only at a subset of $\operatorname{SE}(j, n)$, i.e., a horizontal line segment centered at $(j, n)$ and a vertical line segment starting upward from $(j, n)$ (see Fig. 2). As a result, we may redefine $\operatorname{SE}(j, n)$ to be this subset. This new definition is used in the following sketch of an extension of the the current scheme to a threedimensional Euclidean space $E_{3}\left(x_{1}=x, x_{2}=y\right.$, and $\left.x_{3}=t\right)$.

A SE contains three mutually perpendicular rectangles (see Fig. 4a). The point of intersection is referred to as the center of this SE. The SEs are staggered in both $x$ - and $y$-directions over every half time-step. The CEs are rectangular boxes (see Fig. 4b) also staggered in both $x$ - and $y$-directions over every half time-step. From Fig. $4 \mathrm{~b}$, it is seen that the boundary of a CE can be divided into five parts which, respectively, belong to five neighboring SEs. As a result, the solution procedure described in Section 3 can be easily extended to $E_{3}$.

\section{REFERENCES}

1. R.J. LeVeque, Numerical Methods for Conservation Laws, Birkhäuser Verlag, 1990.

2. S.C. Chang and W.M. To, A New Numerical Framework for Solving Conservation Laws The Method of Space-Time Conservation Element and Solution Element, NASA TM 104495.

3. S.C. Chang and W.M. To, A New Development in the Method of Space-Time Conservation Element and Solution Element - Application to Shock Tube Problem, to appear.

4. G.A. Sod, J. Computational Phys. 27 (1978), 1.

5. S.C. Chang, On An Origin of Numerical Diffusion: Violation of Invariance under SpaceTime Inversion, to appear in the proceeding of 23rd Conference on Modeling and Simulation, April 30 - May 1, 1992, Pittsburgh, PA, USA. 


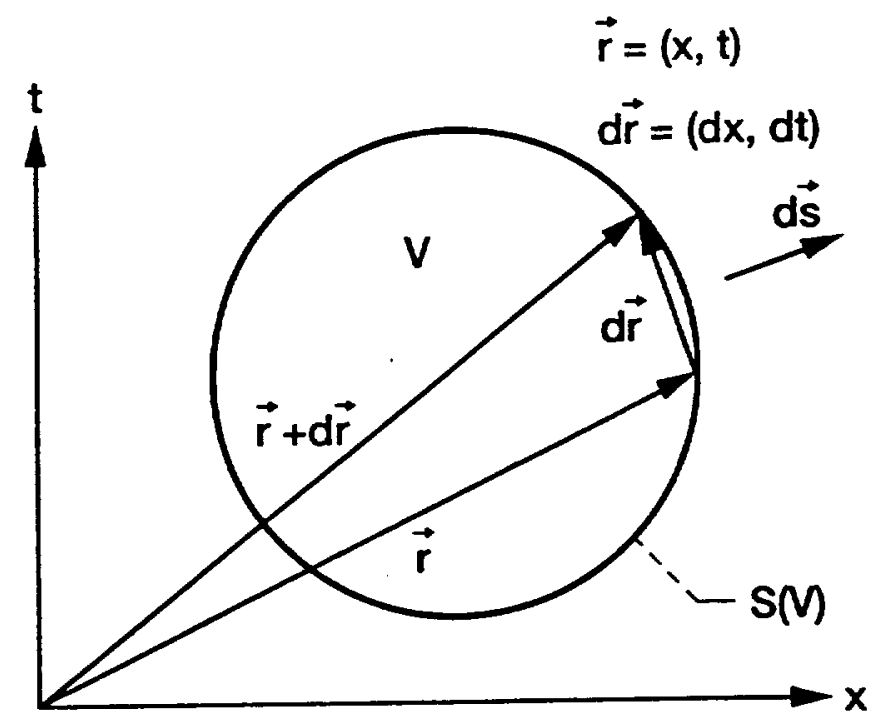

Figure 1.-A surface element $d \vec{s}$ and a line segment $\overrightarrow{d r}$ on the boundary $S M$ of a volume $V$ in a space-time $E_{2}$.

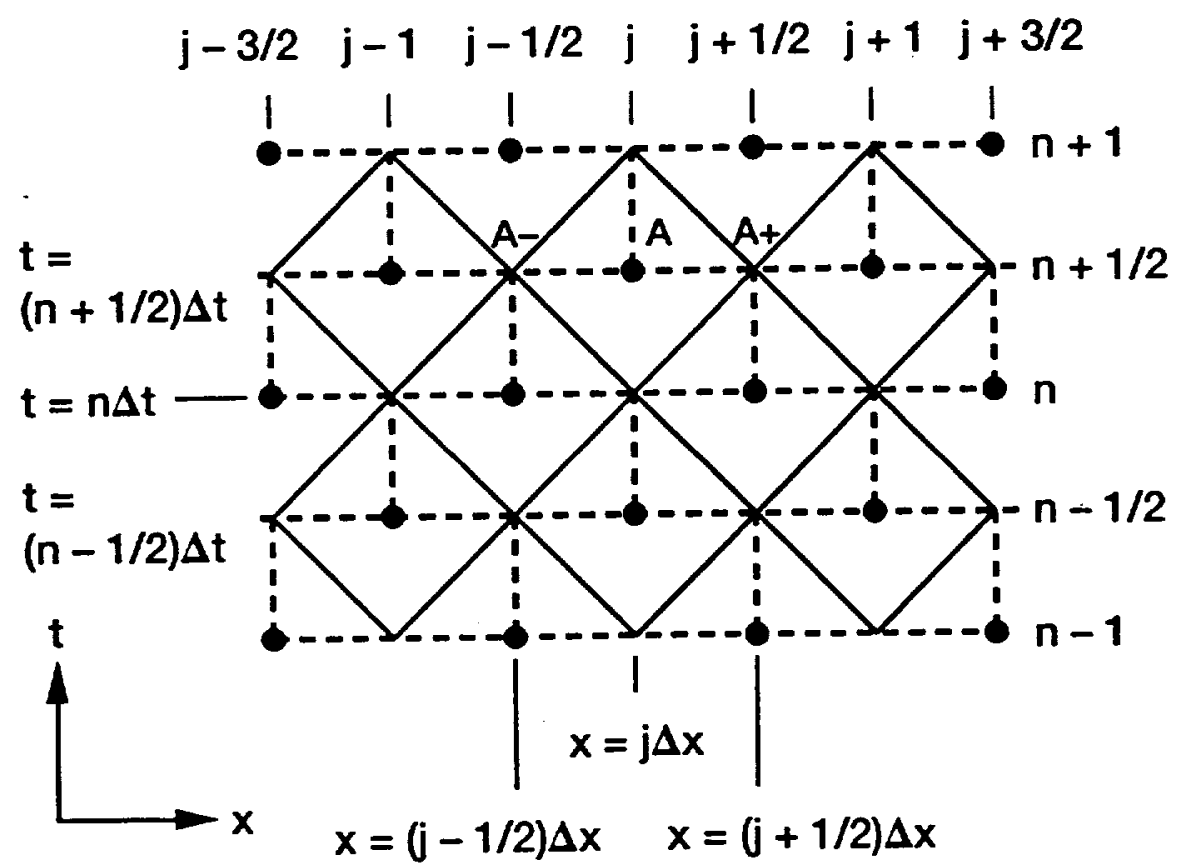

Figure 2.-The SEs (the rhombuses formed by solid lines) and the CEs (the rectangles formed by dashed lines). The dots represent the centers of SEs. 
(a) Pressure $(c=0)$

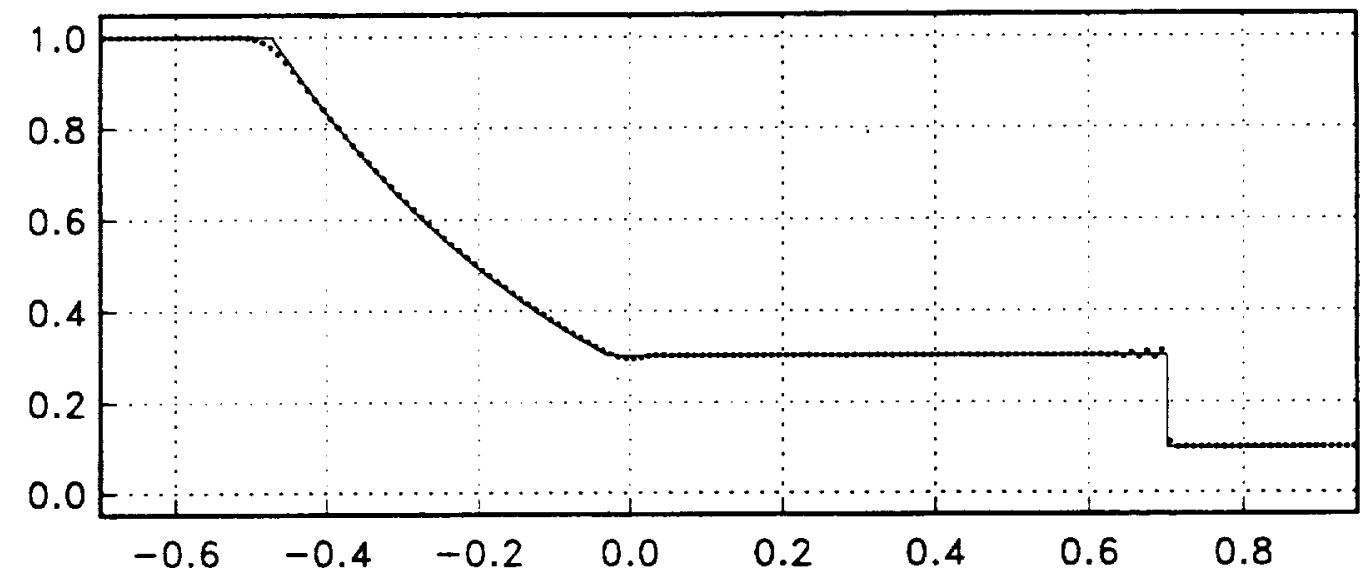

(b) Density $(c=0)$

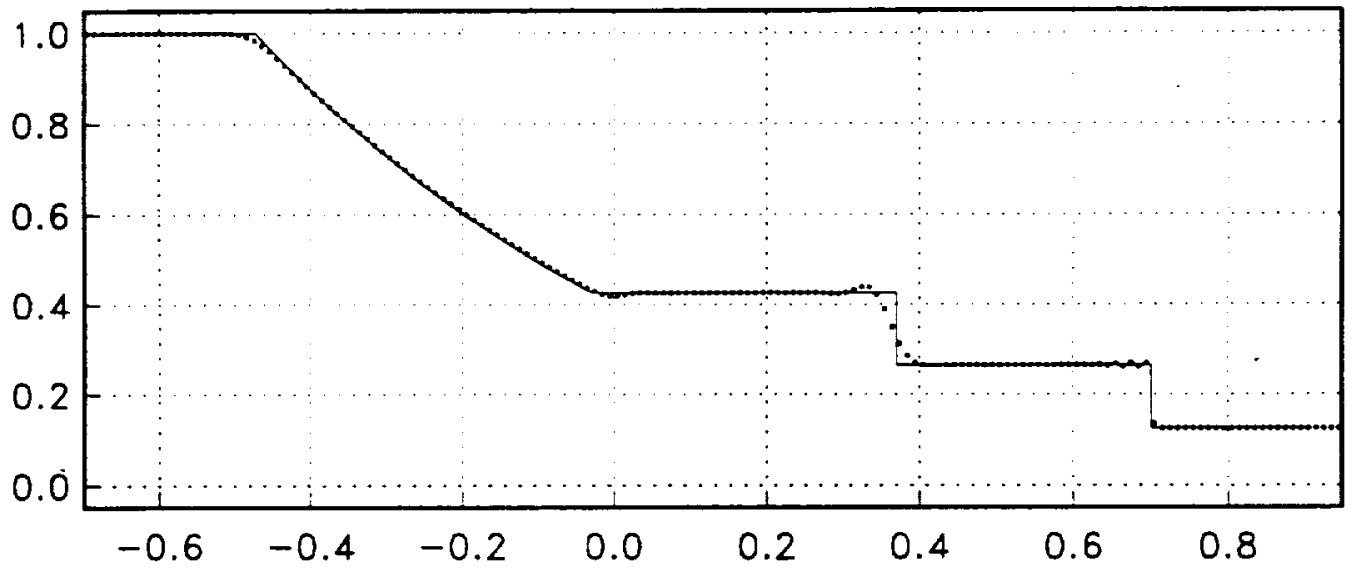

(c) Velocity $(c=0)$

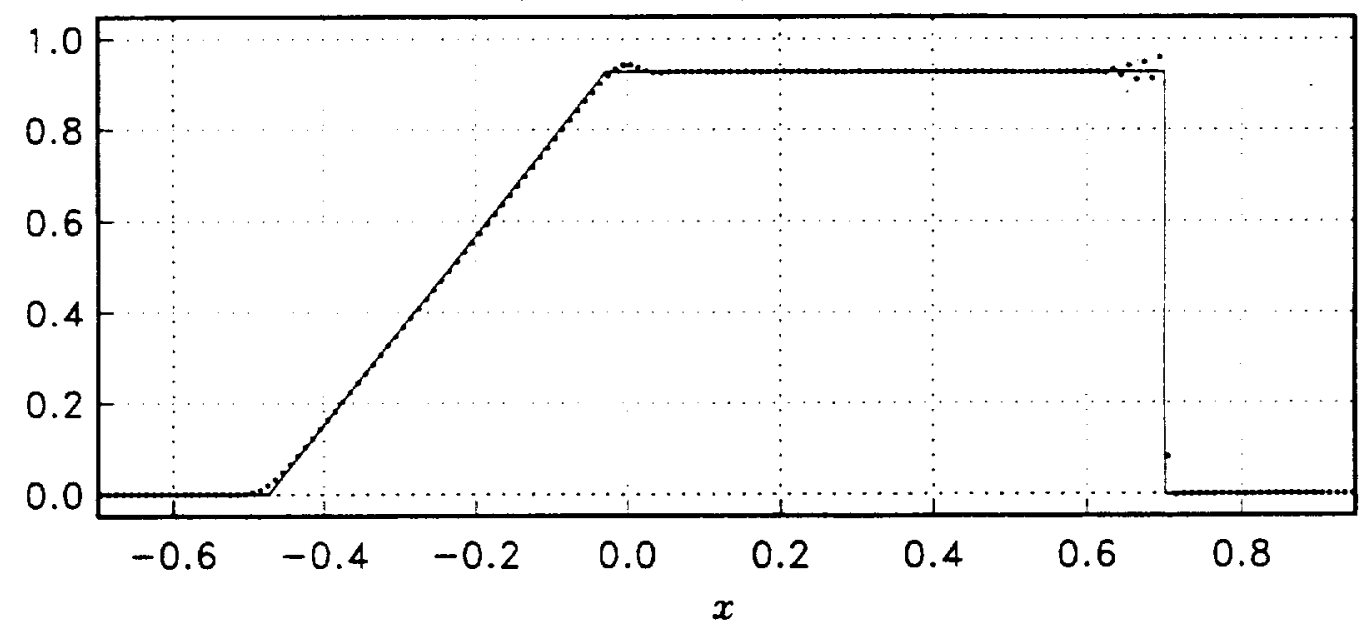

Figure 3. Shock tube solution at $t=0.4$. 
(d) Pressure $(c=1)$

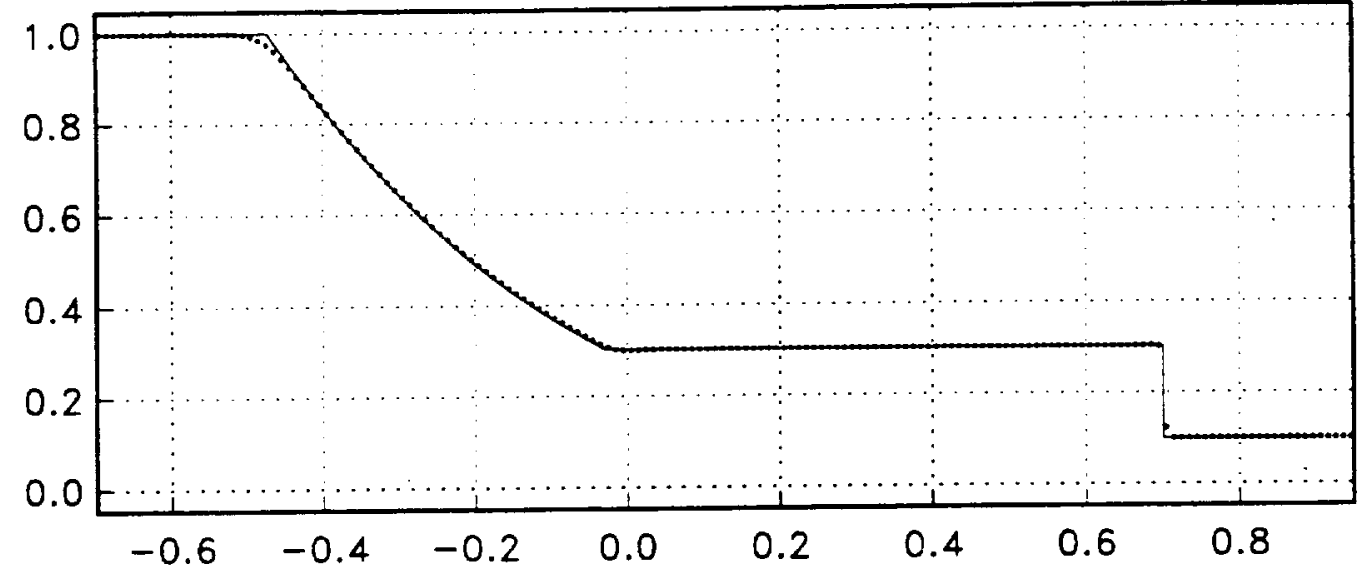

(e) Density $(c=1)$

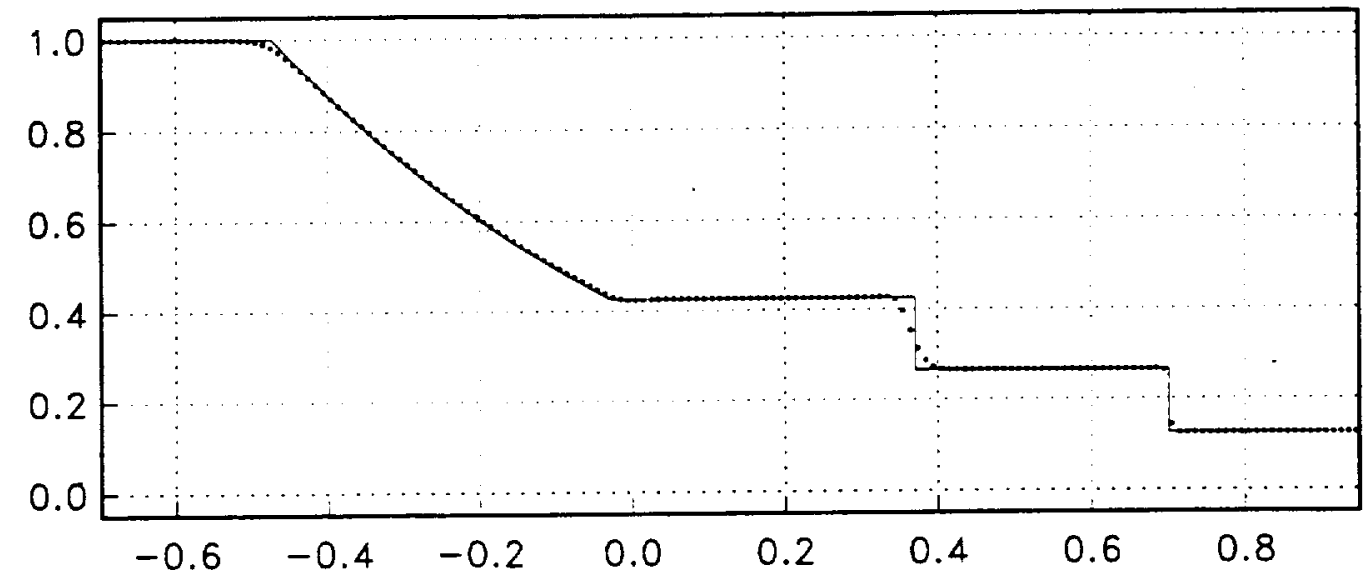

(f) Velocity $(c=1)$

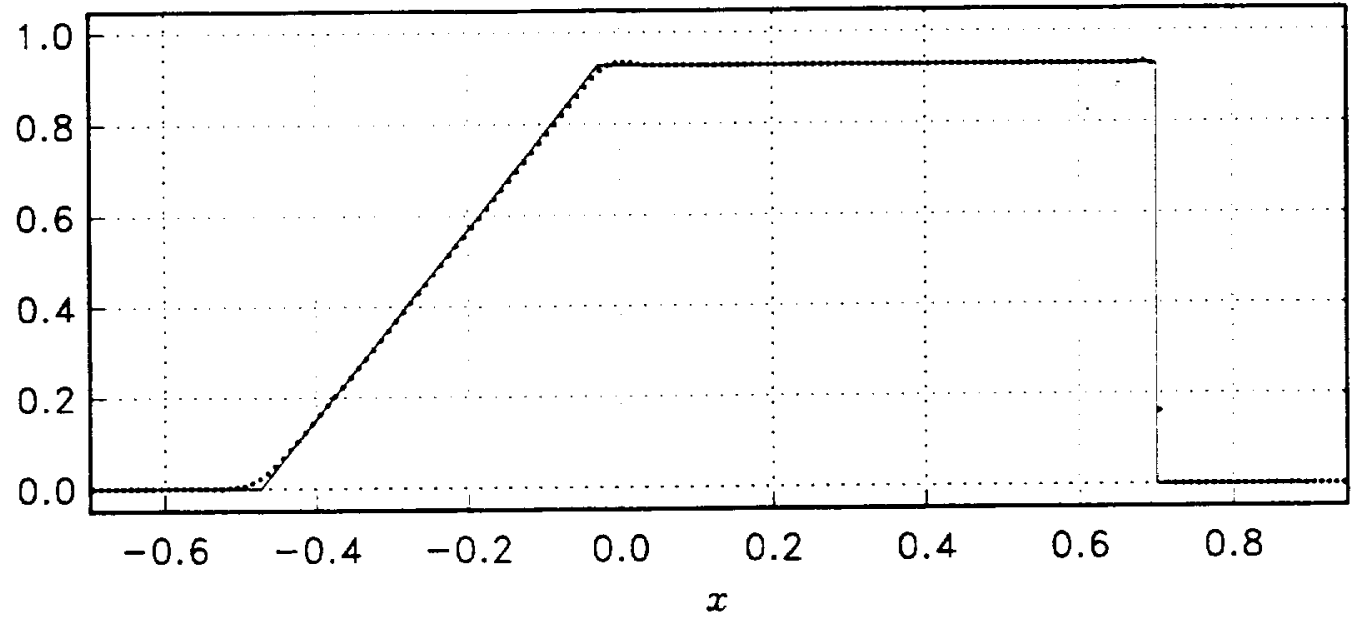

Figure 3 (cont.). Shock tube solution at $t=0.4$. 
(g) Pressure $(c=2)$

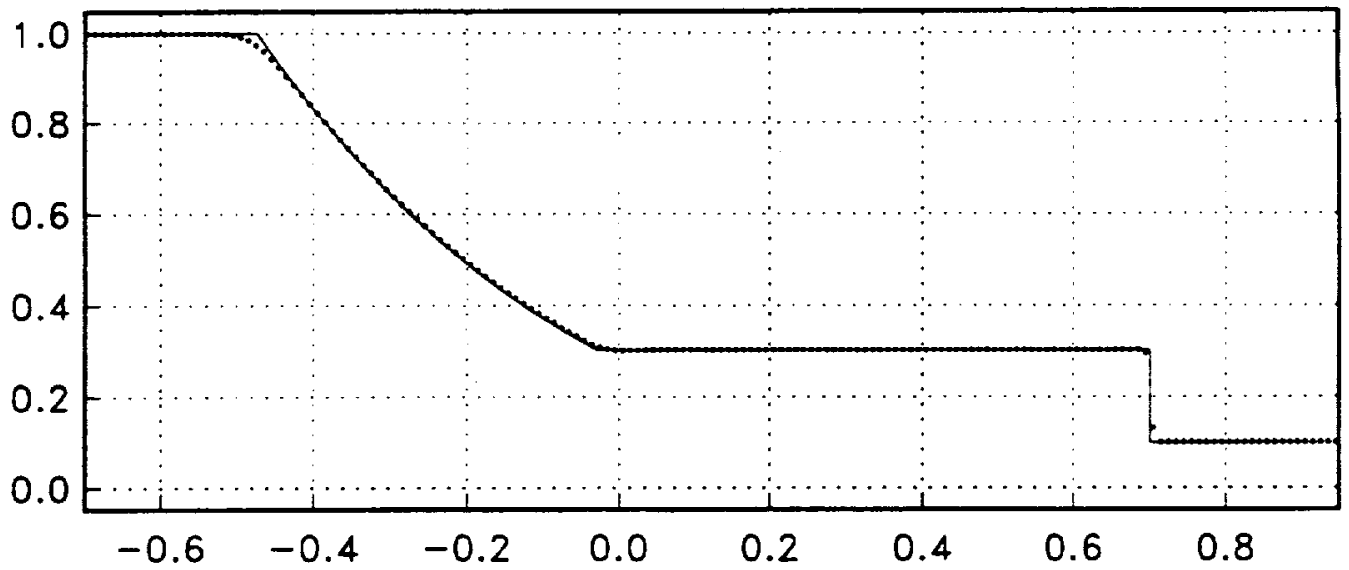

(h) Density $(c=2)$

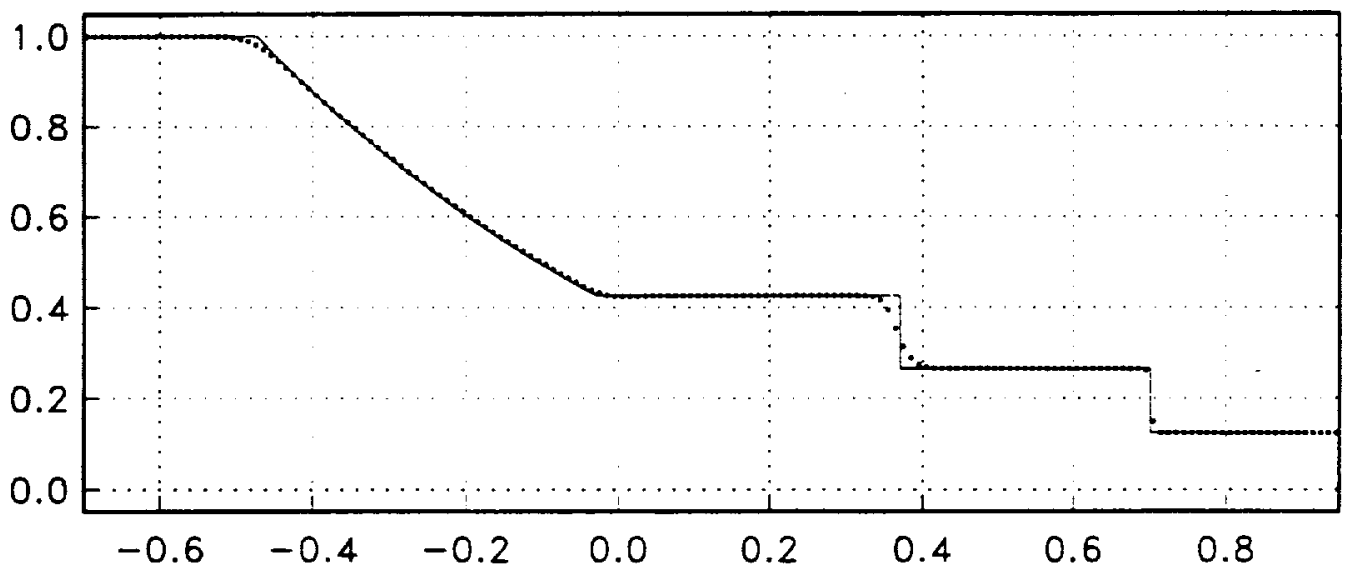

(i) Velocity $(c=2)$

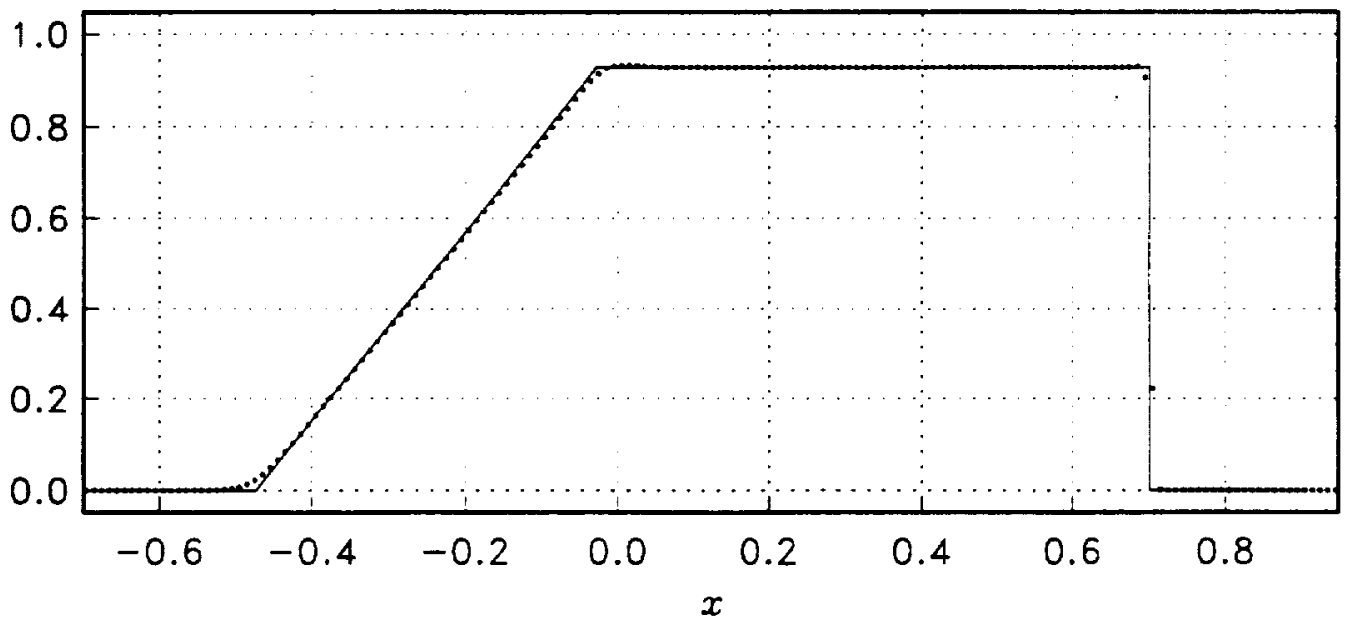

Figure 3 (cont.). Shock tube solution at $t=0.4$. 
(i) Pressure $(c=3)$

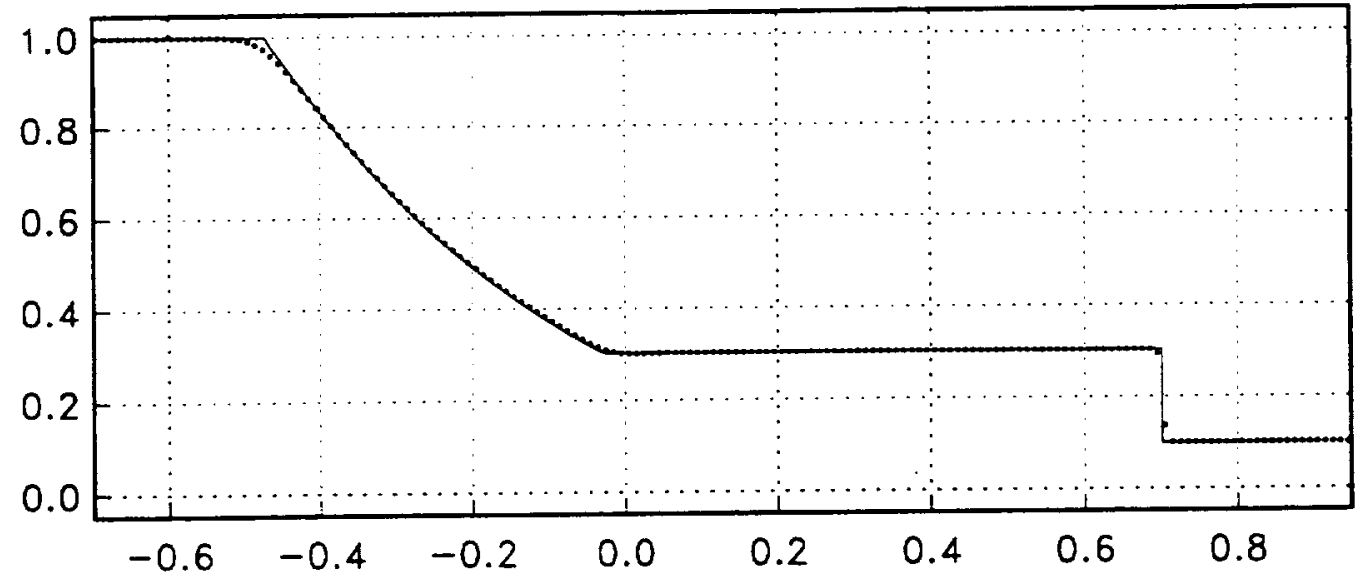

(k) Density $(c=3)$

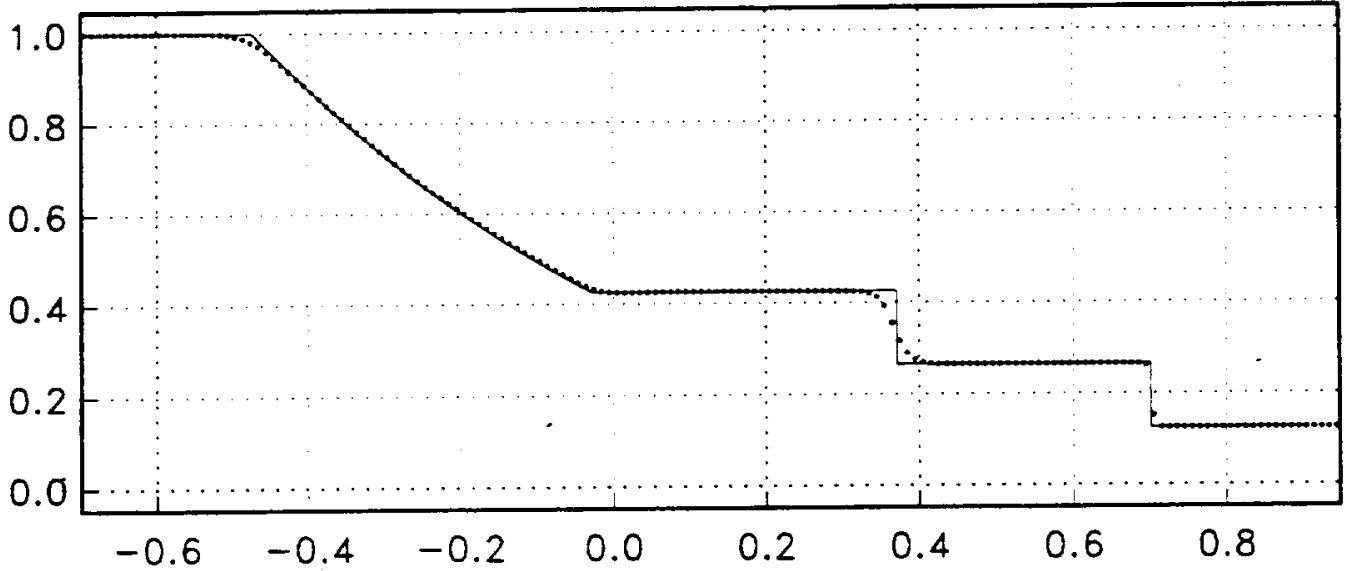

(1) Velocity $(c=3)$

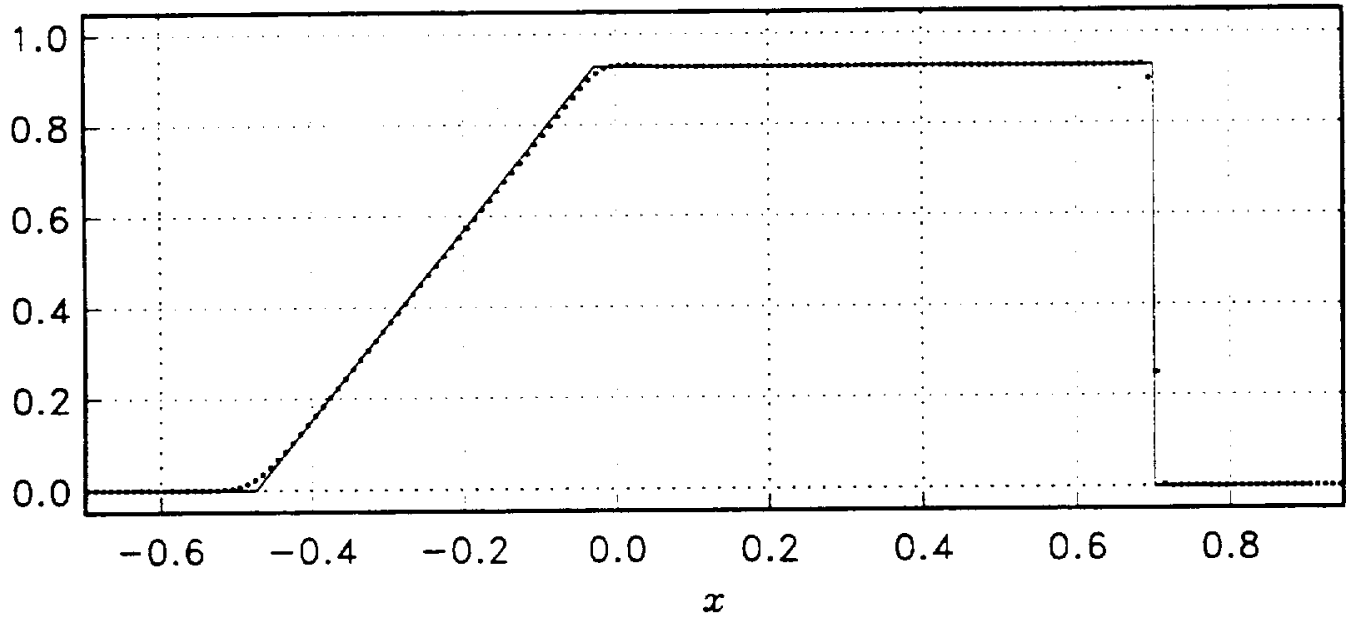

Figure 3 (cont.). Shock tube solution at $t=0.4$. 


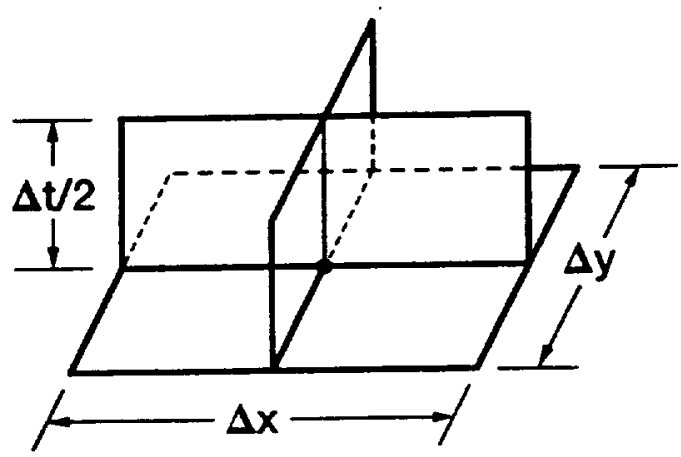

(a)

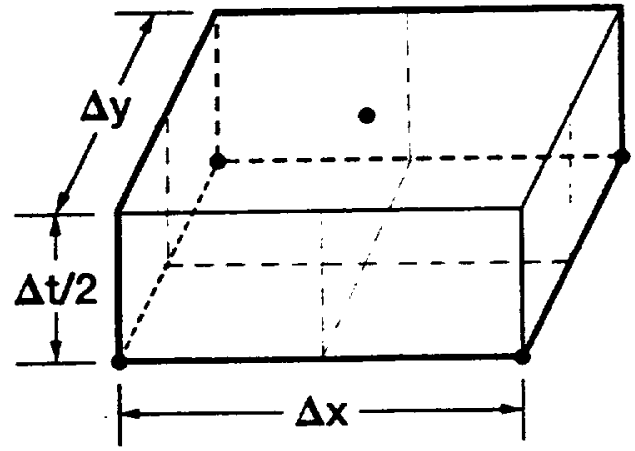

(b)

Figure 4.-A SE and a CE in $E_{3}$. The dots represent the centers of SEs. 
implicit real*8(a-h,o-z)

C

dimension $q 1(1000), q 2(1000), q 3(1000), q 1 \times(1000), q 2 \times(1000)$,

*

$\star$ $q 3 \times(1000), q 1 t(1000), q 2 t(1000), q 3 t(1000), q 1 n(1000)$, $q 2 n(1000), q 3 n(1000), s 1(1000), s 2(1000), s 3(1000)$,

c

$$
\begin{aligned}
& i t=200 \\
& i w=200 \\
& i w i=10 \\
& d t=0.4 d-2 \\
& d x=0.1 d-1 \\
& g a=1.4 d 0 \\
& \text { rhol }=1 . d 0 \\
& \text { ul }=0 . d 0 \\
& \text { pl }=1 . d 0 \\
& \text { rhor }=0.125 d 0 \\
& \text { ur }=0 . d 0 \\
& \text { pr }=0.1 \mathrm{do} \\
& i c=1
\end{aligned}
$$

C

open (unit $=8$, file='for $008^{\prime}$ )

write $(8,10)$ it, iw, iwi, ic

write $(8,20) d t, d x, g a$

write $(8,30)$ rhol,ul,pl

c

write $(8,40)$ rhor,ur,pr

$$
\begin{aligned}
& \mathrm{dt} 1=0.5 \mathrm{do} * \mathrm{dt} \\
& d t 2=d t * \star 2 / 8 . d 0 \\
& h d x=0.5 d 0 * d x \\
& d \times 1=0.25 d 0 * d x \\
& \mathrm{dx2}=0.125 \mathrm{~d} 0 \star \mathrm{dx} \\
& \text { gaI }=g a-1 . d 0 \\
& \text { ga2 }=3 . d 0-g a \\
& \text { ga3 }=0.5 \mathrm{~d} 0 * \mathrm{ga} 2 \\
& \text { ga4 }=0.5 \mathrm{~d} 0 * \mathrm{gal} \\
& \text { qI }(1)=\text { rhol } \\
& \text { q2 }(1)=\text { rhol } * u l \\
& \mathrm{q} 3(1)=\mathrm{pl} / \mathrm{gal}+0.5 \mathrm{do} * \mathrm{rhol} * \mathrm{ul} * \star 2 \\
& \text { g1 (2) = rhor } \\
& \text { q2r }=\text { rhor*ur } \\
& \text { q3r }=\text { pr/gal }+0.5 \text { do*rhor } * u r * \star 2 \\
& q 2(2)=q 2 r \\
& q 3(2)=q 3 r \\
& q 1 \times(1)=0 . \mathrm{do} \\
& q 1 \times(2)=0 . d 0 \\
& q 2 \times(1)=0 . d 0 \\
& q 2 \times(2)=0 . \mathrm{do} \\
& q 3 \times(1)=0 . d 0 \\
& \mathrm{q} 3 \mathrm{x}(2)=0 . \mathrm{do} \\
& \text { q1t }(1)=0 . d 0 \\
& \text { q1t (2) }=0 . d 0 \\
& \text { q2t (1) }=0 . d 0 \\
& \text { q2t (2) }=0 . d 0 \\
& \text { q3t (I) }=0 . \mathrm{do} \\
& q 3 t(2)=0 . d 0 \\
& \mathrm{~m}=2 \\
& \text { do } 600 i=1 \text {, it }
\end{aligned}
$$




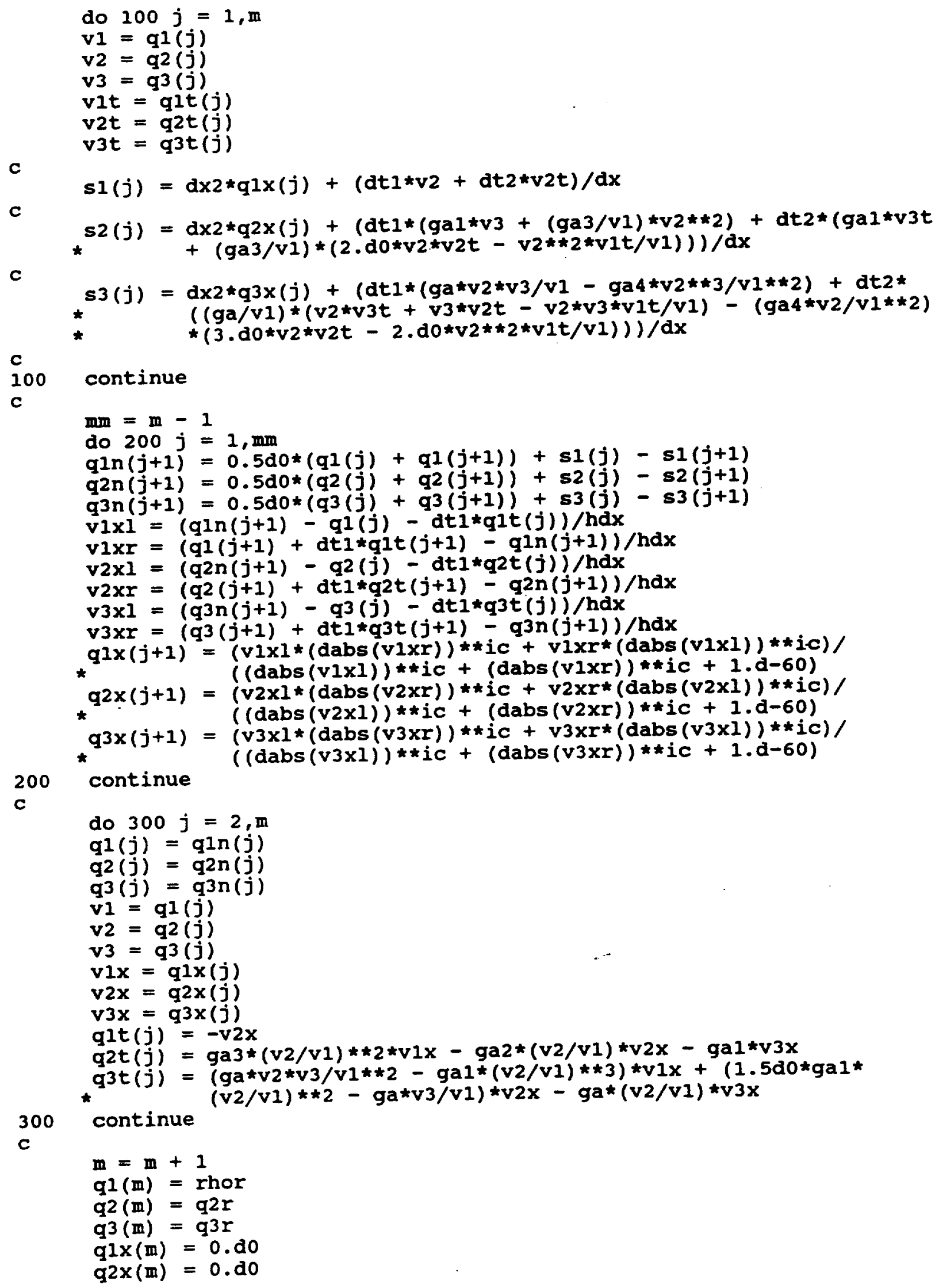

C

c

do $300 \mathrm{j}=2$, Im

$q 1(j)=q \ln (j)$

$q 2(j)=q 2 n(j)$

$q 3(j)=q 3 n(j)$

$v 1=q 1(j)$

$v 2=q 2(j)$

$v 3=q 3(j)$

$v 1 x=q 1 \times(j)$

$v 2 x=q 2 x(j)$

$v 3 x=q 3 x(j)$

$\operatorname{q1t}(j)=-v 2 x$ 


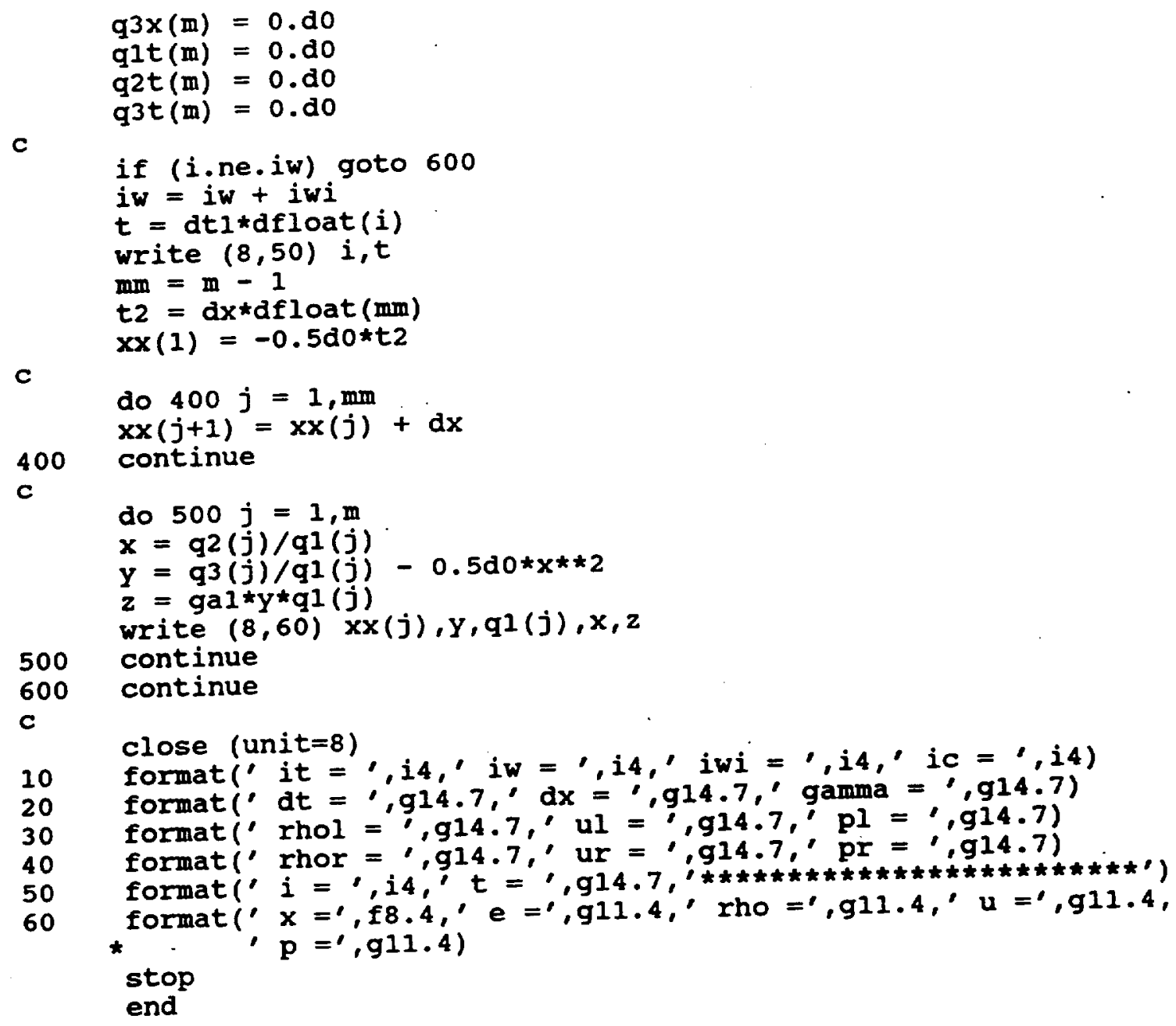




\section{REPORT DOCUMENTATION PAGE}

Pubbc reporting burden for this collection of unformation is estumated to average 1 hout per response. including the time tor reviewing instructions, searching existing cata sources. gathering and maintaining the data needed. and completing and reviewing the collection of inlormation. Send comments regarding this burden estimate or any other aspect of thrs coliection of mlormation, inctuding suggestions for leducing this burden. 10 Washington Headquarters Services. Directorate tor information Operations and Reports, 1215 Jefferson Davis Highway. Sute 1204. Artington, VA 22202-4302, and to the Oftice or Managememt and Budget. Paperwork Reduction Projed (0704-0188). Washungton. DC 20503.
1. AGENCY USE ONLY (Leave Olank)
2. REPORT DATE
July 1992
3. REPOAT TYPE AND DATES COVERED
Technical Mcmorandum

4. TITLE AND SUBTITLE

A Brief Description of a New Numerical Framework for Solving

Conservation Laws-The Method of Space-Time Conservation

Element and Solution Element

6. AUTHOR(S)

Sin-Chung Chang and Wai-Ming To

5. FUNDING NUMBERS

WU-505-62-52

7. PERFORMING ORGANIZATION NAME(S) AND ADDRESS(ES)

8. PERFORMING ORGANIZATION REPORT NUMBER

National Aeronautics and Space Administration

Lewis Research Center

Cleveland, Ohio 44135-3191

E-7169

9. SPONSORINGMONITORING AGENCY NAMES(S) AND ADDRESS(ES)

10. SPONSORING/MONITORING AGENCY REPORT NUMBER

National Aeronautics and Space Administration

Washington, D.C. 20546-0001

NASA TM-105757

11. SUPPLEMENTARY NOTES

Prepared for the 13th Intemational Conference on Numerical Methods in Fluid Dynamics, Rome, Italy, July 6-10, 1992. Sin-Chung Chang, NASA Lewis Research Center, Cleveland, Ohio 44135, and Wai-Ming To, Sverdrup Technology, Inc., Lewis Research Center Group, 2001 Aerospace Parkway, Brook Park, Ohio 44142. Responsible person, Sin-Chung Chang, (216) $433-5874$.

12a. DISTRIBUTION/AVAILABILITY STATEMENT

12b. DISTRIBUTION CODE

Unclassified - Unlimited

Subject Category 64

13. ABSTRACT (Maximum 200 mords)

A new numerical method for solving conservation laws is being developed. It differs substantially from the wellestablished methods, i.e., finite difference, finite volume, finite element, and spectral methods, in both concept and methodology. It is much simpler than a typical high resolution method. No flux limiter or any technique related to characteristics is involved. No artificial viscosity or smoothing is introduced, and no moving mesh is used. Yet this method is capable of generating highly accurate shock tube solutions. The slight numerical overshoot and/or oscillations generated can be removed if a simple averaging formula initially used is replaced by a weighted formula. This modification has little effect on other parts of the solution. Because of its simplicity, generalization of this new method for multi-dimensional problems is straightforward.

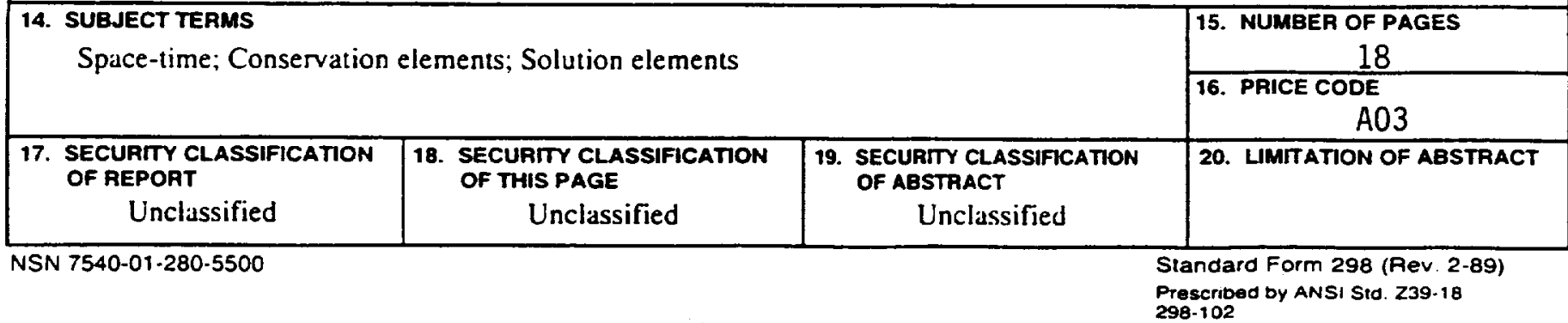


National Aeronautics and

Space Administration

Lewis Research Conter

Cleveland. Ohio 44135

Ormelel Duednews

Penemy tor Privete Ula 5000
FOURTH CLASS MAll

ADDRESS CORRECTION REOUESTED 
